\title{
Studies on the nutrition of marine flatfish. The effect of different dietary fatty acids on the growth and fatty acid composition of turbot (Scophthalmus maximus)
}

\author{
BY C. B. COWEY, J. M. OWEN, J. W. ADRON AND \\ C. MIDDLETON \\ Institute of Marine Biochemistry, St Fittick's Road, Aberdeen $A B{ }_{3} R A$
}

(Received 23 Fanuary 1976 - Accepted 16 March 1976)

\begin{abstract}
I. Five groups of juvenile turbot (Scophthalmus maximus) which had been given a diet free of fat for 12 weeks were given diets in which the lipid component $(\mathrm{g} / \mathrm{kg})$ was; oleic acid alone 50 , oleic acid $40+$ linoleic acid Io, oleic acid $40+$ linolenic acid Io, oleic acid $40+$ arachidonic acid to or oleic acid $40+$ cod-liver oil 10 . These five experimental diets were given for 16 weeks.

2. Weight gains were highest in the group given the diet containing cod-liver oil and lowest in the groups given diets containing oleic acid alone or oleic acid + linoleic acid. Weight gains in the groups given oleic acid + arachidonic acid or linolenic acid were markedly inferior to those of the group given oleic acid + cod-liver oil. It is concluded that arachidonic acid is inferior to polyunsaturated fatty acids of the $\omega_{3}$ series in maintaining growth rate in turbot.

3. Fatty acid analyses of neutral lipids and phospholipids of liver and extrahepatic tissues did not suggest any evidence of desaturation of dietary oleic acid, linoleic acid or linolenic acid by the turbot. These experiments confirm previous isotopic evidence that turbot lack the necessary microsomal desaturases to perform this metabolic transformation.
\end{abstract}

The results of studies at several laboratories during recent years have indicated that rainbow trout (Salmo gairdneri) require dietary fatty acids of the $\omega_{3}$ series for maximal growth, food conversion and freedom from pathology. Castell, Sinnhuber, Wales \& Lee (1972) found that the linolenic acid requirement of rainbow trout is $10 \mathrm{~g} / \mathrm{kg}$ diet or approximately $2.7 \%$ of the dietary energy. Later experiments of Watanabe, Ogino, Koshiishi \& Matsunaga (r974) place the linolenic acid requirement of this species at between 8.3 and $16.6 \mathrm{~g} / \mathrm{kg}$ diet. Trout rapidly elongate and desaturate dietary $\mathrm{C}_{18}$ fatty acids (linoleic acid to arachidonic acid, linolenic acid to docosahexaenoic acid). Both linolenic acid and docosahexaenoic acid given at a level of $10 \mathrm{~g} / \mathrm{kg}$ diet support maximal growth of the fish (Yu \& Sinnhuber, 1972). Dietary linoleic acid does not support maximal growth in trout, and feeding diets containing linoleic acid as the only unsaturated fatty acid result in the appearance of characteristic deficiency symptoms (Castell et al. 1972).

Marine flatfish differ from rainbow trout in important respects in their ability to anabolize dietary fatty acids. When groups of turbot are given diets containing one of three dietary oils (maize oil, cod-liver oil, or hydrogenated coconut oil) weight gain is highest in the fish given a diet containing cod-liver oil and lowest in those given hydrogenated coconut oil. A pathological condition is observed in the adipose tissue of the fish given hydrogenated coconut oil. Moreover, linoleic acid accumulates in the tissues of the group given maize oil (Cowey, Adron, Owen \& Roberts, 1976) with little or no conversion of it to arachidonic acid. The results of further experiments 
(Owen, Adron, Middleton \& Cowey, 1975) suggested that turbot are unable to desaturate orally administered $\left[\mathrm{I}^{14} \mathrm{C}\right]$ linolenic acid. Similarly orally administered $\left[\mathrm{I}-{ }^{14} \mathrm{C}\right]$ oleic acid is not converted to eicosatrienoic acid, nor $\left[\mathrm{I}-{ }^{14} \mathrm{C}\right]$ linolenic acid to docosahexaenoic acid.

As derived long-chain polyunsaturated fatty acids (arachidonic acid) have greater essential fatty acid activity for mammals than do parent shorter-chain precursors such as linoleic acid (Mohrhauer \& Holman, 1963) and as turbot are incapable of chain elongating and desaturating $\mathrm{C}_{14}$ fatty acids at substantial rates the possibility remained that the fatty acid requirements of this species might be met by giving them preformed long-chain polyunsaturated $\omega 6$ acids such as arachidonic acid.

To study this possibility groups of turbot which had previously been given diets free of fat were given diets which contained, as fatty acid complement: oleic acid only, oleic acid + linoleic acid, oleic acid +linolenic acid, oleic acid + arachidonic acid or oleic acid + cod-liver oil.

Weight gains of the turbot given a diet containing oleic acid + arachidonic acid were markedly inferior to those of the turbot given oleic acid + cod-liver oil, indicating that polyunsaturated fatty acids of the $\omega_{3}$ series are necessary for maximal growth in this species. Fatty acid analyses of the fish tissues confirmed the results of the previous isotope experiment (Owen et al. 1975) in that the feeding of oleic, linoleic and linolenic acids led to the accumulation of these fatty acids in the tissues of the fish with no accumulation of eicosatrienoic, arachidonic or docosahexaenoic acids.

\section{EXPERIMENTAL}

The composition of the experimental diets is given in Table $\mathrm{I}$, the diets were prepared as described previously (Cowey, Pope, Adron \& Blair, 1972) and made into moist pellets using an Alexanderwerk pelleting machine (Orthos (Engineering) Ltd, Market Harborough, Leicestershire). The fatty acids used were obtained from Sigma Chemical Co. Ltd, London; DL- $\alpha$-tocopherol (Sigma Chemical Co. Ltd) was added at the rate of $40 \mathrm{mg} / \mathrm{g}$ to each fatty acid on opening the vials and intimately mixed with the fatty acid. This was to retard any air oxidation of the fatty acids during diet preparation.

A portion of the protein content of the experimental diets was provided by a mixture of L-amino acids, this was because previous experience had indicated that such a diet was accepted by the fish while a fat-free diet containing only fish-protein concentrate (Astra Chemicals Ltd, Watford, Herts) as the protein component was rejected by many of them.

Small turbot, about 6 months old, were collected from a sandy beach on the west . coast of Wales. Of these fish, 200 of uniform size were placed in a large tank ( $1 \cdot 8 \times$ $0.9 \times 0.7 \mathrm{~m}$ ) in the Institute aquarium (Cowey, Adron, Blair \& Shanks, 1974) and given an artificial diet (diet I; Cowey, Adron, Brown \& Shanks, 1975) which they accepted readily. After 3 weeks the artificial diet was replaced by the diet free of fat (diet o; Table I) which also proved acceptable to the fish. The turbot were given diet o for 12 weeks. At this time five fish were killed by a sharp blow on the head, and the lipids of their livers and of the remainder of the fish (excluding liver, i.e. extrahepatic 
Table 1. Composition ( $\mathrm{g} / \mathrm{kg} d r y$ diet) of the experimental diets given to turbot (Scophthalmus maximus)

Diet no. ...

Component

Fish-protein concentrate

Dextrin*

Glucose

Oleic acid

Linoleic acid

Linolenic acid

Arachidonic acid

Cod-liver oil

Vitamin premixt

Mineral mixturet

$\alpha$-Cellulose

Amino acid mixturef

Binder\$

0
$466 \cdot 7$
45
45
0
0
0
0
0
28
5
210.4
$149 \cdot 9$
50

1
$466 \cdot 7$
45
45
50
0
0
0
0
28
5
160.4
149.9
50

2
$466 \cdot 7$
45
45
40
10
0
0
0
28
5
$160 \cdot 4$
149.9
50

3

$466 \cdot 7$
45
45
40
0
10
0
0
28
5
160.4
149.9
50

* Retinol (7.2 mg) and cholecalciferol ( $15 \mu \mathrm{g}$ ) supplied in powder form (Rovimix; Roche Products Ltd, Welwyn Garden City, Herts.) in dextrin.

+ As described by Cowey, Pope, Adron \& Blair (1972).

I Supplied (g/kg diet); arginine $6 \cdot 9$, aspartic acid $8 \cdot 5$, threonine $7 \cdot 8$, serine $15 \cdot 2$, glutamic acid $16 \cdot 8$, proline $7 \cdot 0$, glycine 4.8 , alanine $5 \cdot 0$, valine $12 \cdot 7$, isoleucine $11 \cdot 4$, leucine 13.7 , tyrosine $7 \cdot 0$, phenylalanine $9 \cdot 8$, lysine, $7 \cdot 7$, histidine $3 \cdot 6$, methionine $4 \cdot 9$, cystine $4 \cdot 2$, tryptophan $2 \cdot 9$.

$\S$ Carboxymethylcellulose (Cellofas: ICI Ltd, Stevenston, Ayrshire).

tissues) extracted and analysed. Other fish were then randomly assigned to each of five smaller experimental tanks (ten fish/tank; tank size $\mathrm{I} \cdot 0 \times 0.6 \times 0.3 \mathrm{~m}$ ) one fish being transferred at a time to each tank from the large stock tank, then a second fish and so on. The turbot were then given the five experimental diets (diets $1-5$; Table 1 ). Physical conditions in the aquarium, feeding and weighing procedures were as described previously (Cowey et al. 1974).

The experimental diets were given for 16 weeks. Five turbot from each treatment were then killed, and lipids immediately extracted separately from the livers and extrahepatic tissues by the method of Bligh \& Dyer (1959) as modified by Allen, Good, Davis, Chisum \& Fowler (1966). Lipid samples from each extract were separated into neutral and polar lipids, and transmethylated as described by Hornstein, Crowe $\&$ Ruck (1976). Fatty acid methyl esters were separated by gas-liquid chromatography on $1.5 \mathrm{~m} \times 4 \mathrm{~mm}$ glass columns containing roog EGSS-X or EGSS-Y $/ \mathrm{kg}$ Gas Chrom Q (100-120 mesh; Applied Science Laboratories Inc., Pennsylvania, USA). Nitrogen $(50 \mathrm{ml} / \mathrm{min}$ ) was the carrier gas and the gas-liquid chromatograph (Model r 04; Pye Unicam Ltd, Cambridge) was equipped with flame-ionization detectors.

Identification of fatty acids was based on published values for retention times (Ackman, 1967) and comparison with known standards and oils of known composition from marine teleosts.

Fatty acids $20: 3 \omega_{3}$ and $20: 4 \omega 6$ are eluted as a single peak on packed columns (Rivers, Sinclair \& Crawford, 1975 ), other $\mathrm{C}_{20}$ trienes being resolved. Samples of this peak were collected in 'melting point' capillary tubes using a 'splitting' system giving a $10: \mathrm{r}(\mathrm{v} / \mathrm{v})$ division of the effluent from the analytical columns. The samples thus collected were separated into triene and tetraene by thin-layer chromatography using 
Table 2. Initial weights $(g)$, average growth $(g)$ and total food consumption $(g)$ after 16 weeks of turbot (Scophthalamus maximus) given diets containing different fatty acids

\begin{tabular}{|c|c|c|c|c|c|c|}
\hline \multirow{2}{*}{$\begin{array}{l}\text { Diet } \\
\text { no.* }\end{array}$} & \multirow{2}{*}{$\begin{array}{c}\text { No. of } \\
\text { fish }\end{array}$} & \multicolumn{2}{|c|}{ Initial wt } & \multicolumn{2}{|c|}{ Growth } & \multirow{2}{*}{ 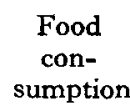 } \\
\hline & & Mean & $\mathrm{SE}$ & Mean & SE & \\
\hline$x$ & 8 & 20.9 & 0.54 & 49 & 0.76 & 89 \\
\hline 2 & 9 & $21 \cdot 7$ & 0.62 & $8 \cdot 6$ & 0.69 & I 55 \\
\hline 3 & 9 & $22 \cdot I$ & 0.69 & $16 \cdot I$ & 0.73 & 190 \\
\hline 4 & IO & $20 \cdot 6$ & 0.48 & 14.8 & 0.85 & 200 \\
\hline 5 & 10 & $20 \cdot 2$ & 0.57 & $32 \cdot 6$ & 0.93 & 330 \\
\hline
\end{tabular}

$0.25 \mathrm{~mm}$ thickness precoated silica gel plates (E. Merck AG, Darmstadt, W. Germany) which had been dipped in a saturated solution of silver nitrate in methanol before activation. The mobile phase was light petroleum (b.p. 40-60 )-diethyl ether $(60: 40, v / v)$. Detection was by charring, and quantitation by densitometry (Model TLD 100 densitometer; Vitatron, N.V., Holland). Only two spots were detected on these plates by this technique. These were identified as triene and tetraene by comparison with 20:4 46 and $18: 3 \omega_{3}$ methyl ester standards. The triene component could only have been $20: 3 \omega_{3}$ because of the retention time of the original peak on the gasliquid chromatogram.

RESULTS

Weight gains of turbot given the experimental diets are given in Table 2. During the eighth week of the experiment mortalities occurred in the groups given diets I (two fish dead), 2 and 3 (one fish dead in each group). These fish were emaciated and appeared not to have eaten the experimental diets. Turbot given diet 5 containing oleic acid + cod-liver oil gained significantly more weight $(P<0.01)$ than those given any other dietary treatment. Fish given diets containing oleic acid + linolenic acid or arachidonic acid (diets 3 and 4 respectively) gained significantly more weight $(P<0.01)$ than those given diets containing oleic acid + linoleic acid (diet 2$)$ or oleic acid alone (diet $\mathrm{I}$ ).

Thus a diet containing a polyunsaturated fatty acid of the $\omega 6$ series was inferior in maintaining growth rate to a diet containing polyunsaturated fatty acids of the $\omega_{3}$ series. This was in part due to the difference in food intake between the two groups (Table 2) but food conversion was also highest in the group given diet 5 and lowest in those given oleic acid alone (diet $\mathrm{I}$ ).

Tables $3,4,5$ and 6 give the proportions of certain fatty acids in the phospholipids and neutral lipids of liver and extrahepatic tissues of turbot given the experimental diets. There are indications that turbot given the diet free of fat (diet 0 ) conserve long-chain polyunsaturated fatty acids in the phospholipids at the expense of neutral lipids. This is certainly true in the liver where levels of docosahexanoic and other long-chain $\omega_{3}$ fatty acids are reduced to low or negligible proportions in the neutral lipids but maintained at relatively high levels in the phospholipids.

The analyses also indicate that no detectable desaturation of the dietary fatty acids 
Table 3. Proportions ( $\mathrm{mg} / \mathrm{g}$ total fatty acids) of oleic, linoleic, linolenic and arachidonic acids and their possible metabolic derivatives in the liver phospholipids of turbot (Scophthalmus maximus) given different dietary fatty acids

(Mean values with their standard errors for five fish/diet)

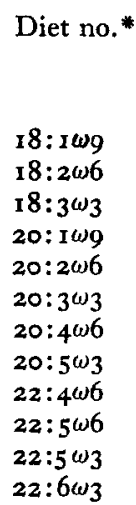

$\begin{array}{rr}\overbrace{\text { Mean }} & \text { SE } \\ 266.8 & 34.9 \\ 33.9 & 7.8 \\ 6.2 & 3.2 \\ 7.3 & 0.7 \\ 1.6 & 0.2 \\ & \text { nd } \\ 15.9 & \\ 40.5 & 4.1 \\ 5.7 & 3.5 \\ 5.7 & 0.5 \\ 22.9 & 4.6 \\ 247.8 & 26.5\end{array}$

\begin{tabular}{rrrr}
$\overbrace{\text { Mean }}$ & SE & $\overbrace{\text { Mean }}$ & \multicolumn{2}{c}{ SE } \\
388.4 & 46.6 & 282.2 & 31.8 \\
20.7 & 6.7 & 264.6 & 20.9 \\
7.7 & 0.4 & 2.3 & 0.4 \\
II.1 & 0.8 & 8.2 & 0.6 \\
1.5 & 0.3 & 13.0 & 1.4 \\
& nd & & nd \\
11.7 & 2.6 & 12.3 & 2.0 \\
20.9 & 8.4 & 14.1 & 3.8 \\
4.0 & 2.4 & 3.1 & 2.5 \\
4.0 & 1.0 & 3.1 & 0.8 \\
19.3 & 4.1 & 11.5 & 2.4 \\
175.9 & 26.9 & 108.1 & 15.1
\end{tabular}

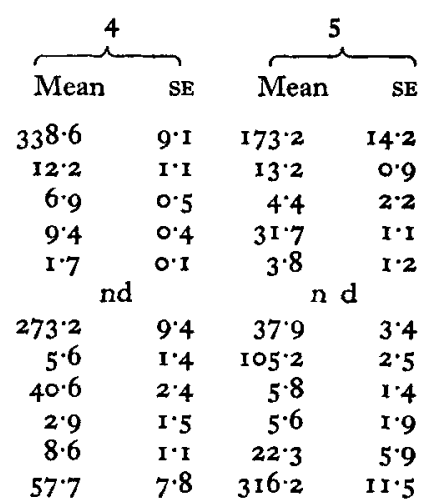

tr, Trace (less than $1 \mathrm{mg} / \mathrm{g}$ total fatty acids); nd, not detected.

* For details, see Table 1 .

Table 4. Proportions (mg/g total fatty acids) of oleic, linoleic, linolenic and arachidomic acids and their possible metabolic derivatives in the liver neutral lipids of turbot (Scophthalmus maximus) given different dietary fatty acids

(Mean values with their standard errors for five fish/diet)

\begin{tabular}{|c|c|c|c|c|c|c|c|c|c|c|c|c|}
\hline \multirow[t]{2}{*}{ Diet no." } & \multicolumn{2}{|l|}{... } & \multicolumn{2}{|c|}{ I } & \multicolumn{2}{|c|}{2} & \multicolumn{2}{|c|}{3} & \multicolumn{2}{|c|}{4} & \multicolumn{2}{|c|}{5} \\
\hline & Mean & $\mathrm{SE}$ & Mean & $\mathbf{S E}$ & Mean & $\mathrm{SE}$ & Mean & SE & Mean & SE & Mean & SE \\
\hline I 8:1 109 & $294 \cdot 4$ & $75 \cdot 5$ & 40477 & $65 \cdot 8$ & $3^{62} \cdot 5$ & $67 \cdot 2$ & $5 \circ 5 \cdot 4$ & $66 \cdot 3$ & 632.4 & $21 \cdot 0$ & $327 \cdot 0$ & $98 \cdot 6$ \\
\hline $18: 2 \omega 6$ & $32 \cdot 1$ & I2.5 & $35 \cdot 4$ & I $x \cdot 9$ & 115.3 & $8 \cdot 4$ & $32 \cdot 8$ & $5 * 7$ & 15.5 & $1 \cdot 0$ & $24 \cdot 1$ & 6.8 \\
\hline $18: 3^{\omega_{3}}$ & $2 \cdot 2$ & $\mathrm{I} \cdot 0$ & $16 \cdot 9$ & $14 \cdot 5$ & $4^{\circ} \circ$ & 0.1 & 55.6 & 0.1 & $9 \cdot 7$ & $2 \cdot 2$ & $6 \cdot 8$ & $2 \cdot 8$ \\
\hline $20: I \omega 9$ & $16 \cdot 1$ & $4 \cdot 2$ & $38 \cdot 0$ & 14.0 & $18 \cdot 1$ & $2 \cdot I$ & $24 \cdot 2$ & 3.8 & $7 \cdot 8$ & 1.0 & 443 & $20 \cdot 2$ \\
\hline $20: 2 \omega 6$ & 2.0 & $0 \cdot I$ & $20 \cdot 5$ & $13 \cdot 1$ & $7 \cdot 4$ & $2 \cdot 0$ & & & & & $2 \cdot 5$ & I.O \\
\hline $20: 3^{\omega_{3}}$ & \multicolumn{2}{|c|}{ nd } & \multicolumn{2}{|c|}{ nd } & \multicolumn{2}{|c|}{ nd } & 17.9 & $7 \cdot 1$ & \multicolumn{2}{|c|}{$\begin{array}{l}\text { tr } \\
\text { nd }\end{array}$} & \multicolumn{2}{|c|}{3 nd } \\
\hline $20: 4 \omega 6$ & $53 \cdot 3$ & $26 \cdot 4$ & $22 \cdot 3$ & $I x \cdot 3$ & $24^{\prime} I$ & $5 \cdot 4$ & $24 \cdot 6$ & $7 \cdot 3$ & $67 \cdot 6$ & 9.5 & $21 \cdot 2$ & $12 \cdot 2$ \\
\hline $20: 5^{\omega} \omega_{3}$ & $27 \cdot 8$ & $2 \cdot 3$ & & & $8 \cdot 7$ & $1 \cdot 7$ & $28 \cdot r$ & $2 \cdot 3$ & & & $69 \cdot 2$ & $2 \cdot 9$ \\
\hline $22: 4 \omega 6$ & $8 \cdot 0$ & 0.5 & 8.0 & $1 \cdot 0$ & $6 \cdot 3$ & 0.1 & & & $7 \cdot 3$ & 0.2 & $4 \cdot 8$ & 0.2 \\
\hline $22: 5 \omega 6$ & & & & & $3 \cdot 3$ & 0.1 & & & & & $2 \cdot 5$ & $I \cdot 4$ \\
\hline $22: 5 \omega_{3}$ & & & 16.7 & r'7 & 5.0 & $1 \cdot 7$ & $4 \cdot 4$ & 0.2 & $18 \cdot 3$ & $I \cdot 3$ & 17.8 & $2 \cdot 8$ \\
\hline $22: 6 \omega_{3}$ & & & 12.4 & 0.1 & $22 \cdot 4$ & 9.1 & 28.0 & $2 \cdot 6$ & 5.7 & $0 \cdot I$ & 145.8 & 18.7 \\
\hline
\end{tabular}

tr, Trace (less than $1 \mathrm{mg} / \mathrm{g}$ total fatty acids); nd, not detected.

* For details, see Table I.

occurred in the tissues of the turbot. This result confirms the isotopic evidence obtained earlier (Owen et al. 1975). Thus oleic acid, which was present in all the experimental diets, accumulated in the tissues of the turbot even when no other dietary fatty acid was given (diet 1 ); no eicosatrienoic acid was found in the tissue lipids of any of the turbot, chain elongation to $20: \mathrm{I} \omega 9$ acid being the only transformation apparent. Similarly there is no evidence of transformation of linoleic, linolenic and arachidonic acids to more unsaturated members of their respective families. 
Table 5. Proportions (mg/g total fatty acids) of oleic, linoleic, linolenic and arachidomic acids and their possible metabolic derivatives in the extrahepatic tissue phospholipids of turbot (Scophthalamus maximus) given different dietary fatty acids

(Mean values with their standard errors for five fish/diet)

\begin{tabular}{|c|c|c|}
\hline Diet no.* & $\ldots$ & \\
\hline $18: 1 \omega_{9}$ & $252 \cdot 9$ & 23.9 \\
\hline 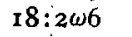 & $25 \circ 0$ & 9 \\
\hline $18: 3 \omega_{3}$ & $5 \cdot 4$ & \\
\hline $20: 1 \omega 9$ & $26 \cdot 8$ & \\
\hline $20: 2 \omega 6$ & 3.7 & \\
\hline $20: 3 \omega_{3}$ & & d \\
\hline $20: 4 \omega 6$ & $29 \cdot 8$ & \\
\hline $20: 5^{\omega_{3}}$ & $86 \cdot 2$ & \\
\hline $22: 4 \omega 6$ & $4 \cdot 6$ & \\
\hline $22: 5 \omega 6$ & 9.4 & \\
\hline $22: 5 \omega_{3}$ & $33 \cdot 0$ & \\
\hline $22: 6 \omega_{3}$ & 201.7 & \\
\hline
\end{tabular}

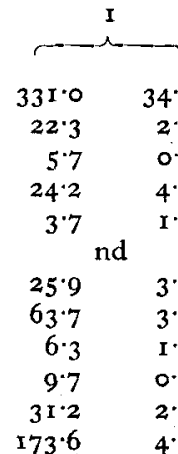

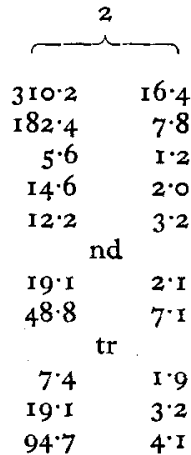

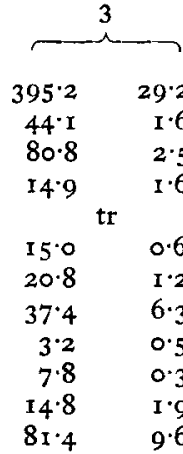

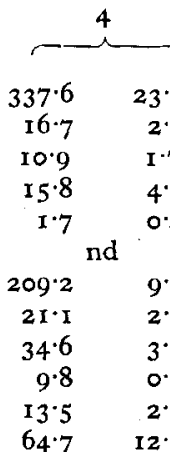

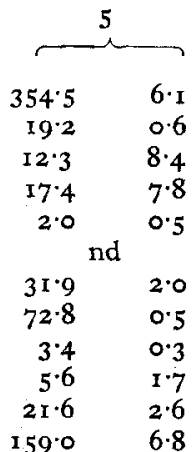

tr, Trace (less than I $\mathrm{mg} / \mathrm{g}$ total fatty acids); nd, not detected.

* For details, see Table I.

Table 6. Proportions ( $\mathrm{mg} / \mathrm{g}$ total fatty acids) of oleic, linoleic, linolenic and arachidonic acids and their possible metabolic derivatives in the extrahepatic tissue neutral lipids of turbot (Scophthalmus maximus) given different dietary fatty acids

(Mean values with their standard errors for five fish/diet)

\begin{tabular}{|c|c|c|}
\hline Diet no.* & $\ldots$ & \\
\hline & Mean & SE \\
\hline $18: 1 \omega 9$ & $28 I^{\prime} 2$ & $12 \cdot 7$ \\
\hline I8:2w6 & $22 \cdot 6$ & $5 \cdot 7$ \\
\hline $18: 3^{\omega_{3}}$ & 5.7 & $x \cdot 7$ \\
\hline $20: 1 \omega_{9}$ & $39 \cdot 0$ & $12 \cdot 9$ \\
\hline $20: 2 \omega 6$ & $3 \cdot 5$ & 0.6 \\
\hline $20: 3 \omega_{3}$ & & \\
\hline $20: 4 \omega 6$ & $32 \cdot 2$ & $5^{\cdot 2}$ \\
\hline $20: 5^{\omega_{3}}$ & $46 \cdot 8$ & $6 \cdot 2$ \\
\hline $22: 466$ & 9.0 & $4 \cdot 3$ \\
\hline $22: 5 \omega 6$ & $30 \cdot 4$ & 9.7 \\
\hline $22: 5 \omega_{3}$ & 25.7 & $2 \cdot 6$ \\
\hline $22: 6 \omega_{3}$ & $149^{\circ} 2$ & $18 \cdot 2$ \\
\hline
\end{tabular}

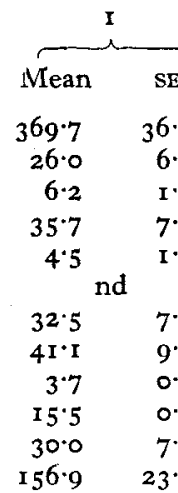

\begin{tabular}{|c|c|c|c|}
\hline \multicolumn{2}{|c|}{2} & \multicolumn{2}{|c|}{3} \\
\hline Mean & $\mathrm{SE}$ & Mean & $\mathrm{SE}$ \\
\hline $3^{69} \cdot 9$ & $28 \cdot 2$ & $429^{\circ} \mathrm{I}$ & $38 \cdot 0$ \\
\hline I $58 \cdot 3$ & 15.5 & $35^{\prime 2}$ & 2.4 \\
\hline $3 \cdot 7$ & $I \cdot 3$ & $90 \cdot 1$ & $7 \cdot 5$ \\
\hline 20.1 & 3.9 & 19.6 & $3 \cdot 3$ \\
\hline I $2 \cdot 2$ & $3 \cdot 2$ & $3 \cdot 8$ & I.2 \\
\hline \multicolumn{2}{|c|}{ nd } & $18 \cdot 7$ & 0.5 \\
\hline $24^{\prime} I$ & $4 \cdot 4$ & 25.8 & $I \cdot 5$ \\
\hline $28 \cdot 4$ & $7^{\circ} 9$ & 28.7 & $6 \cdot 5$ \\
\hline $3 \cdot 8$ & 0.9 & $4: 0$ & $I \cdot 3$ \\
\hline $12 \cdot 5$ & $I \cdot O$ & 13.7 & $5 \cdot 7$ \\
\hline 20.9 & $3 \cdot 1$ & 17.5 & $2 \cdot 6$ \\
\hline $93 \cdot \mathbf{I}$ & 30.0 & $82 \cdot 5$ & I9. I \\
\hline
\end{tabular}

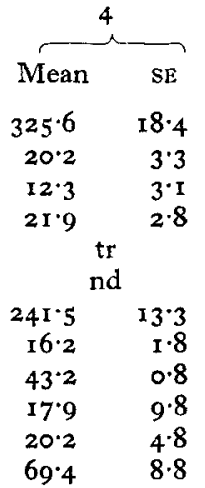

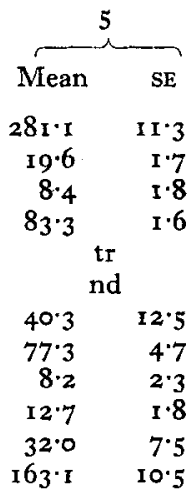

$\mathrm{tr}$, Trace (less than $\mathrm{I} \mathrm{mg} / \mathrm{g}$ total fatty acids); nd, not detected.

* For details, see Table I.

There are indications that chain elongation of dietary fatty acids occurred to a limited extent. Thus 20:3 $\omega_{3}$ acid was found only in the lipids of those turbot given a dietary supply of linolenic acid, 20:266 acid was present in higher relative amounts in the lipids of fish given linoleic acid in the diet (diet 2) than in the lipids of fish given other dietary fatty acids, similarly 22:4w6 acid occurred in higher relative amounts in the lipids of fish given arachidonic acid than in those of fish given other dietary fatty acids. Thus the present analyses confirm the isotopic evidence concerning chain elongation. 


\section{DISCUSSION}

The results presented here indicated that growth rate and food conversion of turbot given a dietary supply of a pre-formed polyunsaturated fatty acid of the $\omega 6$ series is inferior to that of turbot given a dietary supply of polyunsaturated $\omega_{3}$ fatty acids. To this extent fatty acid requirements of turbot cannot be met by arachidonic acid, and long-chain $\omega_{3}$ polyunsaturated fatty acids must be supplied in the diet for maximal growth.

The inability of turbot to desaturate $\mathrm{C}_{18}$ fatty acids has also been confirmed. The absence of the relevant desaturase enzymes is not unique to the turbot, nor marine flatfish in general, for it has recently been reported that the essential fatty acid requirements of the cat (Felis catus) can only be satisfied by a diet containing derived essential fatty acids (Rivers et al. 1975). This similarity in nutritional requirement between two such separately evolved vertebrates is of considerable interest from the viewpoint of comparative nutrition. It suggests that extreme carnivores, despite having very different environments, have evolved in common metabolic ways. In this regard it is of interest that the cat and the turbot may also have similarities in glucose metabolism. Thus Ballard (1965) was unable to detect glucokinase (EC 2.7.r.2) activity in the cat while Cowey et al. (1975) were unable to induce this enzyme in plaice (Pleuronectes platessa).

Close comparison of our analyses on turbot with those of Rivers et al. (1975) on cats is not really possible because different diets were used and while our results refer to phospholipids and neutral lipids of liver and extrahepatic tissues their results apply specifically to choline phosphoglycerides of plasma. In general, they found a greater accumulation of parent fatty acid (linoleic acid) and a greater reduction in derived fatty acids in choline phosphoglycerides of the cat than did we in turbot tissues. This is not surprising as plasma phospholipids of the cat are likely to have much higher turnover rates than are mixed tissue phospholipids of the cold-blooded turbot, in addition Rivers et al. (1975) gave their experimental diets for a much longer period (about I 5 months).

The fatty acid composition of phosphoglycerides of certain tissues of those fish which possess the ability to desaturate fatty acids is related to the environmental temperature at which they are reared. Thus a membrane fraction from the intestinal mucosa of goldfish (Carrasius auratus) adapted to an environmental temperature of $3^{\circ}$ contained much higher proportions of unsaturated $\mathrm{C}_{20}$ and $\mathrm{C}_{22}$ fatty acids than did the same fraction isolated from goldfish adapted to temperatures of $30^{\circ}$ (Kemp \& Smith, 1970). Presumably at lower environmental temperatures higher proportions of polyunsaturated fatty acids are necessary in the phospholipids to maintain membrane integrity and fluidity.

Recently it was found in another freshwater fish, Pimelodus maculatus, which also possesses the ability to desaturate $\mathrm{C}_{18}$ fatty acids (Ninno, De Torrengo, Castuma $\&$ Brenner, 1974) that microsomal desaturase activity, measured at $35^{\circ}$, was markedly greater in fish acclimatized for 3 weeks to a water temperature of $15^{\circ}$ than was desaturase activity in fish reared at $29^{\circ}$. 
Thus it appears that the requirement of fish for polyunsaturated fatty acids is affected by environmental temperature and those fish such as turbot which cannot desaturate $\mathrm{C}_{18}$ fatty acids are likely to have higher requirements for derived fatty acids (polyunsaturated $\mathrm{C}_{20}, \mathrm{C}_{22}$ ) when reared at low temperatures $\left(5^{-10^{\circ}}\right)$ than when reared at higher temperatures $\left(15^{-20^{\circ}}\right)$.

\section{REFERENCES}

Ackman, R. G. (1967). Lipids 2, 502.

Allen, C. F., Good, P., Davis, H. F., Chisum, P. \& Fowler, S. D. (1966). F. Am. Oil Chem. Soc. 43, 223.

Ballard, F. J. (1965). Comp. Biochem. Physiol. 14, 437.

Bligh, E. G. \& Dyer, W. J. (1959). Can. F. Biochem. Physiol. 37, 911.

Castell, J. D., Sinnhuber, R. O., Wales, J. H. \& Lee, J. D. (1972). Y. Nutr. roz, 77.

Cowey, C. B., Adron, J. W., Blair, A. \& Shanks, A. M. (1974). Br. F. Nutr. 31, 297.

Cowey, C. B., Adron, J. W., Brown, D. A. \& Shanks, A. M. (1975). Br. J. Nutr. 33, 219.

Cowey, C. B., Adron, J. W., Owen, J. M. \& Roberts, R. J. (1976). Comp. Biochem. Physiol. 53B, 399.

Cowey, C. B., Pope, J. A., Adron, J. W. \& Blair, A. (1972). Br. F. Nutr. $28,447$.

Hornstein, I., Crowe, P. F. \& Ruck, J. B. (1967). Analyt. Chem. 39, 352.

Kemp, P. \& Smith, M. W. (1970). Biochem. Y. II7, 9.

Mohrhauer, H. \& Holman, R. T. (1963). F. Nutr. 8r, 67.

Ninno, R. E., De Torrengo, M. A. P., Castuma, J. C. \& Brenner, R. R. (1974). Biochim. biophys. Acta 360,124 .

Owen, J. M., Adron, J. W., Middleton, C. \& Cowey, C. B. (1975). Lipids ro, 528.

Rivers, J. P. W., Sinclair, A. J. \& Crawford, M. A. (1975). Nature, New Biol. 258, 17 I.

Watanabe, T., Ogino, C., Koshiishi, Y. \& Matsunaga, T. (1974). Bull. Jap. Soc. scient. Fish. 40, 493.

Yu, T. C. \& Sinnhuber, R. O. (1972). Lipids 7, $45^{\circ}$. 